\title{
Experimental Study of the Multiple Factors of Cu-Mo Bulk Flotation Xiaoying Guan ${ }^{\mathrm{a}}$, Yongsheng Song ${ }^{\mathrm{b}}$, Wenjuan $\mathrm{Li}^{\mathrm{c}}$ \\ National Engineering Lab. of Biohydrometallurgy, General Reasearch Institute for Nonferrous Metals, Beijing \\ aguanxiaoying0305@sina.com, bsysmba@163.com, juanzi88888@126.com
}

Keywords: Chalcopyrite; Molybdenite; Bulk flotation; Multiple factors

Abstract. The present work mainly focuses on the influencing factors concerning copper molybdenum bulk flotation. Test samples which using four kinds of $-100+200$ mesh pure minerals contain $\mathrm{Cu}: 0.4 \%$, Mo:0.04\%, S:3\% respectively. The bulk flotation results show that using z-200+ kerosene as collectors in $\mathrm{Cu}-\mathrm{Mo}$ mixed flotation, at $\mathrm{pH}=12$, Cu-Mo bulk concentrate was obtained with the copper grade of $27.545 \%$ and recovery of $92.832 \%$, and molybdenum grade of $2.737 \%$ and recovery of $92.091 \%$.

\section{Introduction}

Copper and molybdenum in the ore mainly locates in Porphyry Copper Deposits and Skarn Copper Deposits. ${ }^{[1]}$ In recent decades, the large-scale development and utilization of the Porphyry Copper Molybdenum ore has resulted in the exhaustion of easy mining ore, leading to the existing Porphyry Copper Molybdenum ore grade becoming lower and lower. In production practice, Copper Molybdenum ore flotation process is usually divided into two loops : the $\mathrm{Cu}-\mathrm{Mo}$ bulk flotation and the $\mathrm{Cu}$-Mo separation flotation . Recycling the purpose minerals as much as possible, which means to improve the recovery of copper and molybdenum is the most significant thing in $\mathrm{Cu}-\mathrm{Mo}$ bulk flotation process. In this paper, the effects of $\mathrm{pH}$, regulation of agent, and others on the recoveries of copper and molybdenum in the bulk flotation process were studied.

\section{Test samples and materials}

Chalcopyrite and Pyrite were purchased from a mine of Hunan province and Tongling mineral products Co., Ltd, respectively. According to the sample preparation process shown in Figure 1, the two rich ore block were broken to $-2 \mathrm{~mm}$ after hand selected, respectively. $-100+200$ mesh ore were obtained after porcelain ball mill and wet sieve combined with a closed circuit grinding process. Then the ore was purified by magnetic separation, flotation and shaking table separations. After that, cleaning and sealing preservation.

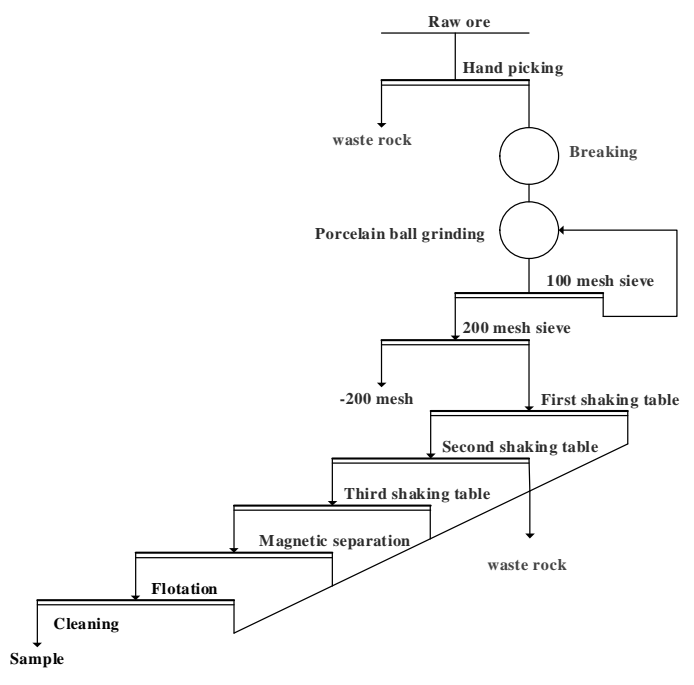

Fig.1 Sample preparation process 
The concentrate powder of molybdenum was purchased from Zouping molybdenum industry Inc. Shandong. The chemical analysis indicates that the purity of the molybdenite achieves test requirements without purification. The molybdenite powder with $-100+200$ mesh which meet the demand of the experiment was obtained by screening test, and sealed up.

The quartz was purchased from Victory quartz sand factory in Fengyang, Anhui. The quartz samples were disposed by $10 \%$ solutions of dilute hydrochloric acid to remove the impurities such as iron. After that, cleaning the surface of the quartz samples to neutral with deionized water repeatedly.

The purity of chalcopyrite, pyritization, molybdenite and quartz were shown in Table 1 . The flotation water includes buffer solution prepared with deionized water and other $\mathrm{pH}$ solutions regulated by sulfuric acid, $\mathrm{NaOH}$, lime, and $\mathrm{NaCO}$, respectively. The principles of buffer solution preparation are that the concentration of the buffer reagent is as low as possible, and buffer solution should have enough buffer ability.

Table 1. Sample purity and the chemical analysis results of the major compositions of the ore
\begin{tabular}{lllllll} 
Sample & $\mathrm{Cu}(\%)$ & $\mathrm{Fe}(\%)$ & $\mathrm{Mo}(\%)$ & $\mathrm{SiO}_{2}(\%)$ & $\mathrm{S}(\%)$ & Purity (\%) \\
\hline Chalcopyrite & 32.22 & 31.70 & & 31.27 & 93.24 \\
$\begin{array}{l}\text { Pyrite } \\
\text { Molybdenite }\end{array}$ & 0.01481 & 46.51 & & 47.65 & 89.34 \\
Quartz & 0.6548 & 0.5503 & 55.72 & & 32.90 & 92.95 \\
\end{tabular}

\section{Experimental procedures}

Flotation experiment: according to the chemical analysis results, the four purified minerals were mixed in a certain proportion as test sample which contains $\mathrm{Cu}: 0.4 \%, \mathrm{Mo}: 0.04 \%, \mathrm{~S}: 3 \%$. First, put $10 \mathrm{~g}$ sample into the beaker $(100 \mathrm{ml})$, then add $40 \mathrm{ml}$ distilled water, treated with ultrasonic washer for 5 minutes, poured out the supernatant.After that, transfer the sample into $30 \mathrm{ml}$ flotation cell of small trough flotation machine. Adjusted flotation machine speed at 1992 $\mathrm{r} / \mathrm{min}$. Through the mixing process, studying the flotation behaviors of chalcopyrite and molybdenite in a variety of different conditions. As show in Fig. 2(a)-Fig. 2(d).

Chemical analysis: grinding the flotation concentrate and tailings to -400 mesh with agate mortar, Sampling to analysis the element content of $\mathrm{Cu}, \mathrm{Fe}, \mathrm{Mo}$. Recovery rate can be calculated by the formula: $\varepsilon=\gamma \times \beta / \alpha \times 100 \%$. In the formula: $\varepsilon$ : the product recovery rate of a component $(\%) ; \alpha$ : the grade of certain component in the ore $(\%) ; \beta$ : the grade of certain component in the product $(\%) ; \gamma$ : product yield $(\%)$.
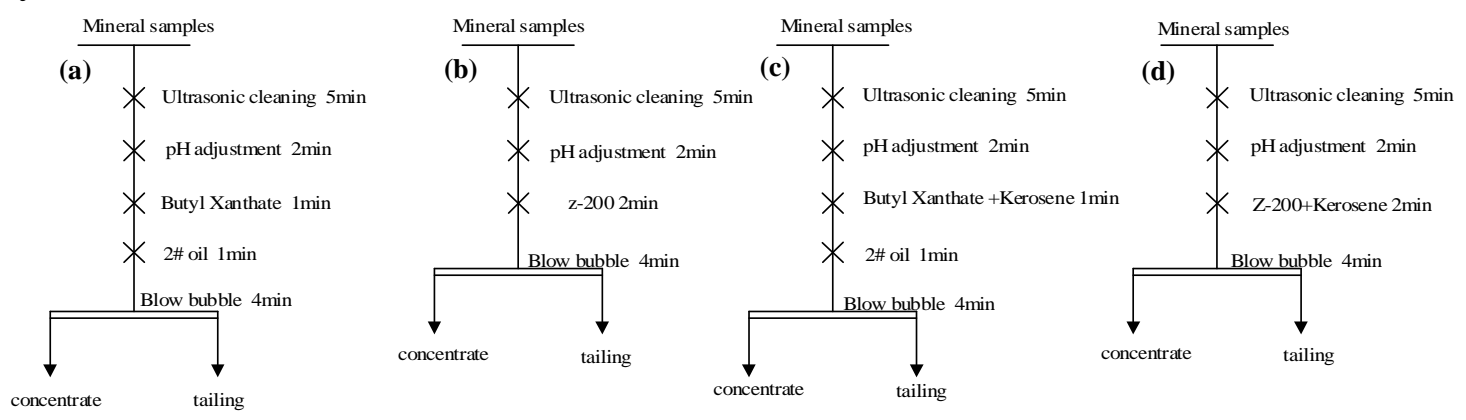

Fig.2(a) Flotation process of butyl xanthate; (b) Flotation process of z-200; (c) Flotation process of butyl xanthate and kerosene; (d) Flotation process of $\mathrm{z}-200$ and kerosene

\section{Results and discussion}

pH test According to the flotation flow sheet shown in Fig. 2(b), fixed z - $200(20 \mathrm{~g} / \mathrm{t})$ as collector, examine the flotability of chalcopyrite and molybdenite under different $\mathrm{pHs}$.

Buffer solution system As shown in Fig. 3(a), with the increasing of $\mathrm{pH}$, the recovery rate of copper and molybdenum show the same tendency, reaching the highest value when $\mathrm{pH}=12$. At this point, the grades of copper and molybdenum are also at a higher position. Above $\mathrm{pH} 12$, the recovery rate and grade sharply decline. (The dotted line represents the recovery rate of $50 \%$, the same below) 
Sulphuric acid system and natural pH system As shown in Fig. 3(b), the recovery rates of copper and molybdenum in the acid condition have a little changes. the recovery rates of copper and molybdenum increased when the $\mathrm{pH}$ rose to the natural $\mathrm{pH}=7$. Copper grade and molybdenum grade changed little.
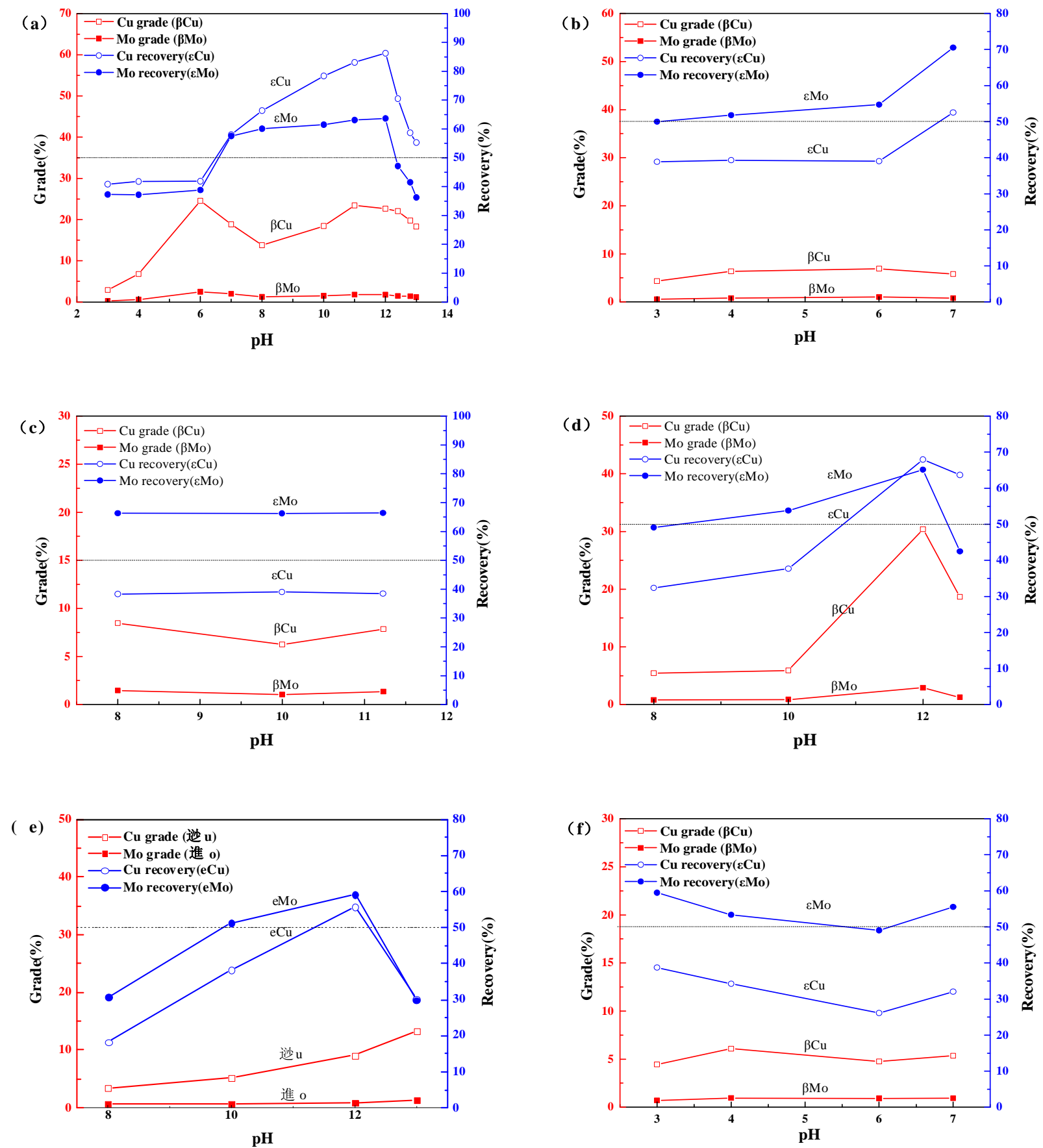

Fig.3(a) pH test of buffer solution system; (b) pH test of sulphuric acid and natural pH system; (c) pH test of sodium carbonate system; (d) pH test of buffer solution system; (e)pH test of sodium hydroxide system; (f) $\mathrm{pH}$ test of sulphuric acid and natural $\mathrm{pH}$ system when butyl xanthate as collector

Sodium carbonate system As shown in the Fig. 3(c), the recovery rate of copper and molybdenum kept stable. Throughout the whole $\mathrm{pH}$ range, the recovery rate of molybdenum was higher than copper.

Lime system As illustrated in Fig. 3(d): The grade of $\mathrm{Cu}$ and Mo, as well as the recovery rate show a slow increasing trend when $\mathrm{pH}$ from 8 to 10 . Then, these indexes increased rapidly. Until rough concentrate grade and recovery rate both reach optimal quantity at $\mathrm{pH}=12$, then goes into reverse. In addition, Mo's recovery rate is better than $\mathrm{Cu}$ below $\mathrm{pH}=12$. 
Sodium hydroxide system In the Fig. 3(e), as the inclination of $\mathrm{pH}$, the recovery rate of copper and molybdenum decreased after increasing. Cu's grade increased slightly while Mo's kept stable. The flotation experiment reach optimal quantity at $\mathrm{pH}=12$ in the Sodium hydroxide system.

\section{Butyl xanthate as collector in Sulfuric acid and natural pH system}

In the Fig. 3(f), considering the butyl xanthate has a good flotation performance under the weak acidic conditions, it is necessary to add a set of tests which study the recovery of $\mathrm{Cu}$ and Mo in sulfuric acid and natural $\mathrm{pH}$ environment with the butyl xanthate as collector.

Copper is the most important target element in Copper and molybdenum ore, so the recovery of copper is the main point . Comparison the copper's recovery rate in acidic environment and alkaline environment shown in the Fig. 4(a),(b), respectively. Analyzing these experimental results.

\section{Result discussions of acid and neutral systems}

a.The variation of Copper recovery in the buffer system and sulfuric acid system have the same trend when $\mathrm{z}-200$ is used as the collector.

b.The results of $\mathrm{pH}$ tests in the sulfuric acid system of the two kinds of collectors are shown that with the increasing of $\mathrm{pH}$, the grade and recovery of $\mathrm{Cu}$ and Mo increased slightly, while butyl xanthate show a opposite tendency.

\section{Result discussions of alkalic system}

a.The copper's recovery of the buffer system is higher than the others.

b.Lime is not only a kind of alkali, but also an depressor of pyrite. The effect of the lime is to produce $\mathrm{OH}^{-}$.Pyrite surface generate ferric hydroxide hydrophilic film in the alkaline pulp, so that pyrite is inhibited. Another effect of lime on the inhibition of pyrite was providing $\mathrm{Ca}^{2+}$ to produce undissolved $\mathrm{CaSO}_{4}$ in the pyrite surface.

c. $\mathrm{NaOH}$ is alkali, the reaction of $\mathrm{OH}^{-}$and pyrite surface iron generates hydrophilic thin film of ferric hydroxide, thereby inhibiting pyrite flotation.

d.Sodium carbonate is a salt of strong alkali weak acid, a much weaker alkaline modifier than lime. With a certain buffer function, $\mathrm{pH}$ is more stable in the flotation process. ${ }^{[2]}$ At the same time, sodium carbonate has the activation function. When the dosage of the collector is certain, the sodium carbonate can preferentially activate pyrite, which takes up the resources of the medicament, and influences the flotation of copper and molybdenum. Therefore, Copper's recovery rate is lower than other systems, and haven't changed much.
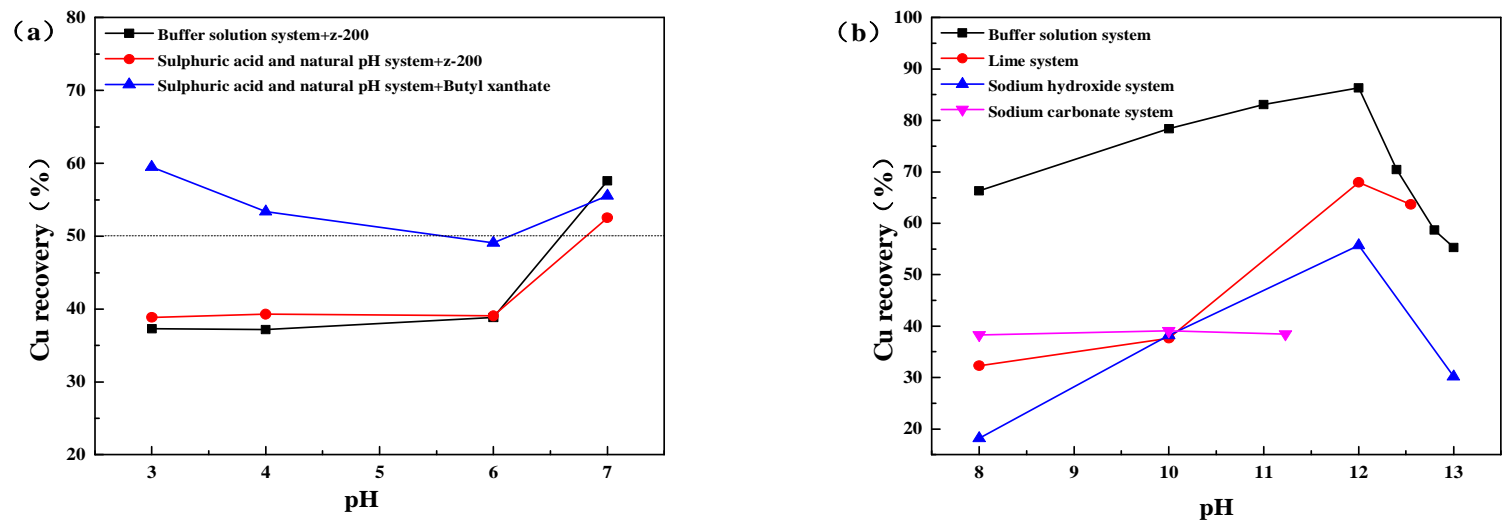

Fig.4(a) Comparison of copper recovery in acidic and natural pH system; (b) Comparison of copper recovery in acidic and natural pH system

PH test conclusion: under acidic conditions with butyl xanthate as collector, as acidity increased, the copper's recovery rate is getting better and better, but taking into account damage of equipment and deterioration of the environment, the acidic environment will not be considered. Therefore, Lime is chosen as $\mathrm{pH}$ modifier, and fixed $\mathrm{pH}=12$ to carry out the next test.

Type and dosage of the collector According to the results of $\mathrm{pH}$ test, fixed $\mathrm{pH}$ to 12 ( regulated by lime), and the type and dosage of the collectors were tested. Four kinds of pharmaceutical plans are shown in Figure 3.2. 
Z-200 z-200 has the characteristic of little dosage and weak collecting ability to pyrite. In the Fig. 5 (a), with the increase of Z-200 dosage, the recovery rate of copper and molybdenum increase. When the dosage was $55 \mathrm{~g} / \mathrm{t}$, the recovery rate of copper and molybdenum reached the highest, then the recovery rate of copper and molybdenum increased slowly. With the increase of dosage, the grade of copper decreased slightly, and the change of molybdenum's grade was little.

Butyl xanthate In the Fig. 5(b), When the dosage of butyl xanthate was small, the grade and recovery rate increased with the increase of reagent, and when the reagent dosage exceeded a certain value, the grades of $\mathrm{Cu}$, Mo decreased. This is because the formation of insoluble metal xanthogenate. ${ }^{[3]}$

Butyl xanthate and copper ion generates xanthate copper and butyl xanthate and iron generates xanthate iron. The solubility product of xanthate copper is smaller than xanthate iron. The smaller the solubility product, the easier ion exchange adsorption, the better the collecting ability of butyl xanthate is. So when the dosage is excessive, butyl xanthate will receive pyrite and other target minerals, leading to the declination of copper molybdenum grade.

The dosage of kerosene when fixing z-200 55g/t In the Fig. 5(c), with the increasing amount of kerosene, copper molybdenum's recovery rate declined. The grade of copper declined slightly, molybdenum grade changed little. Adding kerosene after z-200 in flotation process, we found the defoaming phenomenon which resulting in the deterioration of flotation.

The dosage of kerosene when fixing butyl xanthate $20 \mathrm{~g} / \mathrm{t}$ In the Fig. 5(d), with the adding of kerosene, the recovery rate of copper molybdenum decreased. The possible reason was that the adding of kerosene led to the oil film between the bubble and the ore particle become thick, the oil molecules easily break off and the ore particles fall off from the air bubble, so as to deteriorate the flotation effect. $^{[2]}$
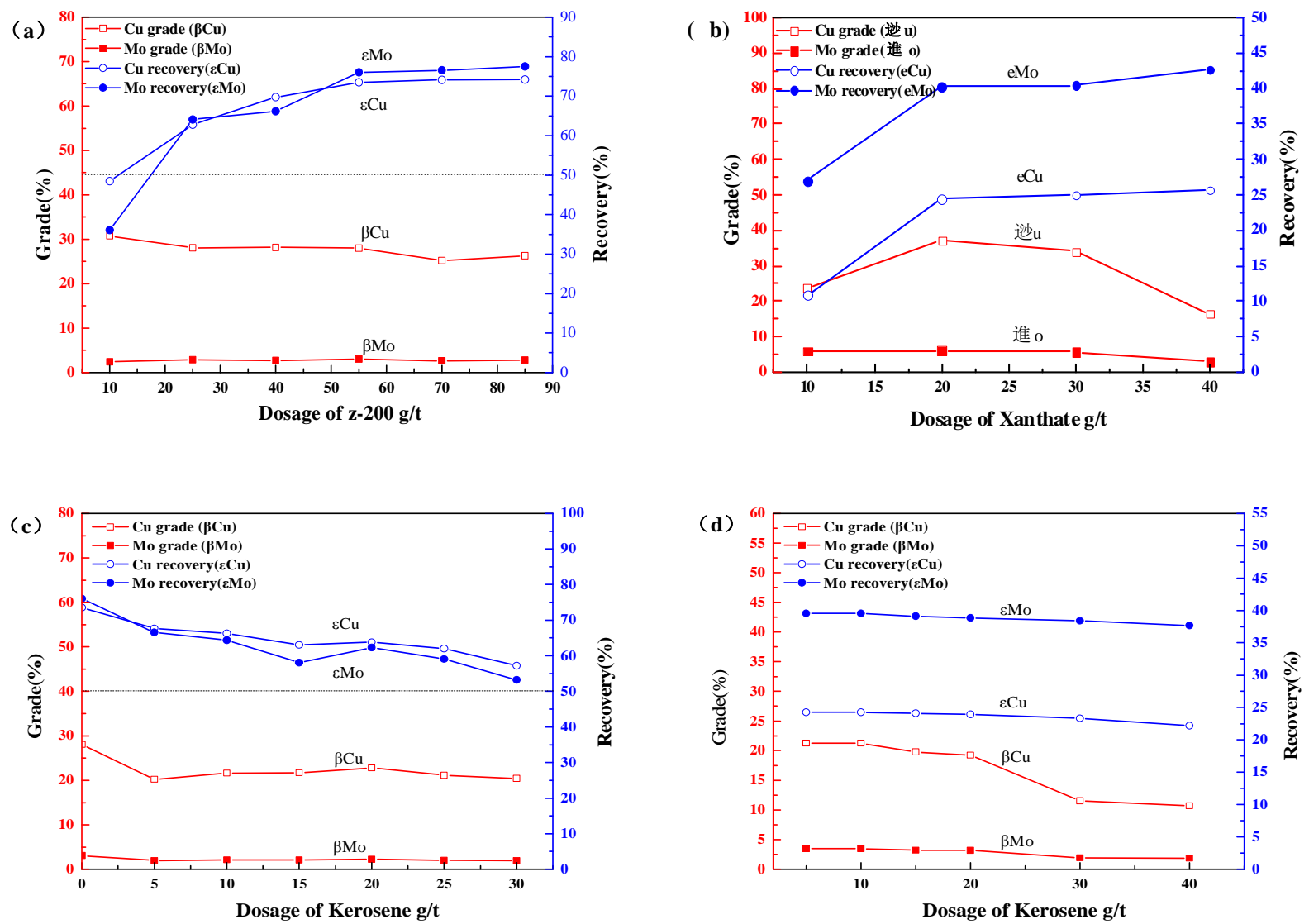

Fig.5(a) Test of the dosage of z-200; (b) Test of the dosage of butyl xanthate; (c)Test of the dosage of kerosene when fixing z-200 55g/t; (d) Test of the dosage of kerosene when fixing butyl xanthate $20 \mathrm{~g} / \mathrm{t}$

Stirring time after adding kerosene Mixed with an appropriate amount of kerosene and polar collector can enhance the adsorption strength of polar collector on the surface of mineral, enhancing the hydrophobicity of mineral surface and increasing the effect of trapping. ${ }^{[4]}$ In this experiment, 
however, after adding kerosene, appeared the phenomenon of transient bubble elimination, which leaded to poor foaming effect, and deteriorated flotation effect.

Analyze the experimentation reasons, may be the stirring time after dosing was too short. Kerosene was not fully dispersed. Kerosene oil droplets were too large, worse the flotation effect. Therefore, increasing the stirring time after dosing kerosene, so the kerosene in the pulp can fully disperse, interact with other reagents and obtain better collecting effect.

In the Fig. 6(a), when fixed pH=12, z-200 40g/t, kerosene10g/t, 2\# oil 10g/t, with the increase of the stirring time, the recovery rate of copper and molybdenum were all improved, then tend to be stable. In the Fig. 6(b), when fixed $\mathrm{pH}=12$, butyl xanthate $20 \mathrm{~g} / \mathrm{t}$, kerosene $15 \mathrm{~g} / \mathrm{t}, 2 \#$ oil $10 \mathrm{~g} / \mathrm{t}$, the recovery rate of copper and molybdenum increase with the increase of stirring time. When the stirring time is over $18 \mathrm{mins}$, the grade is greatly decreased.So when $\mathrm{pH}=12, \mathrm{z}-20040 \mathrm{~g} / \mathrm{t}$, kerosene $10 \mathrm{~g} / \mathrm{t}, 2 \#$ oil $10 \mathrm{~g} / \mathrm{t}$, stirring time 26min. The best indexes are obtained.
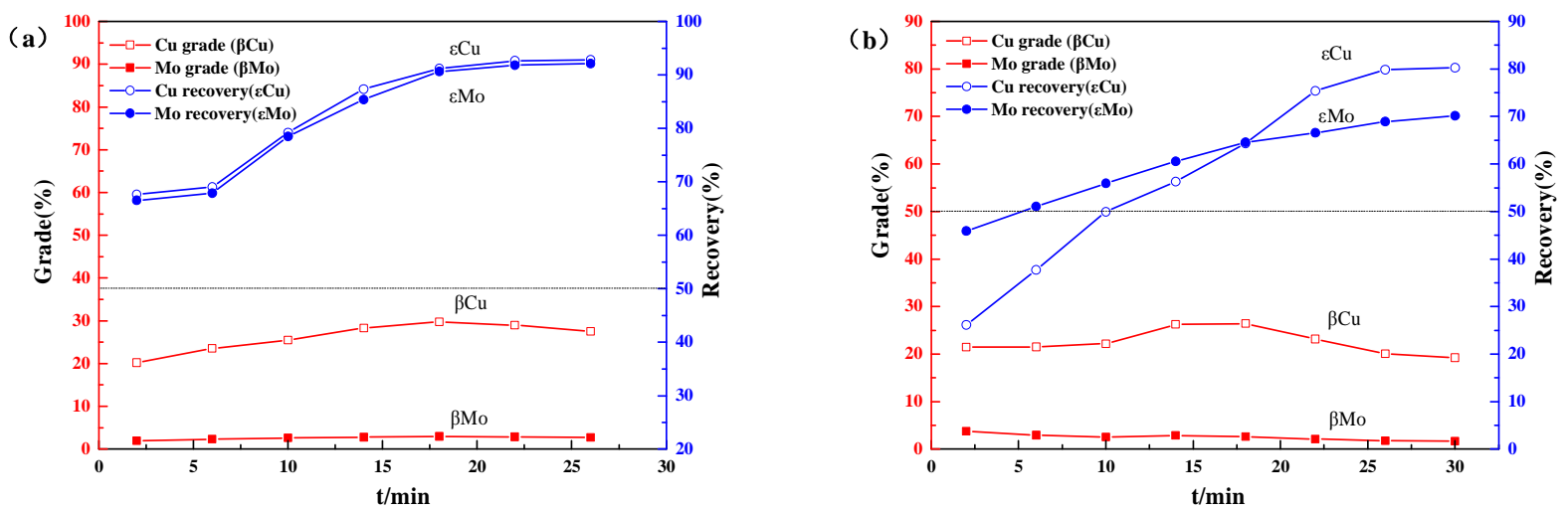

Fig.6(a) Stirring time after adding z-200 and kerosene; (b) Stirring time after adding butyl xanthate and kerosene

\section{Conclusions}

(1)The optimal $\mathrm{pH}$ of $\mathrm{Cu}-\mathrm{Mo}$ bulk flotation was 12 , which regulated by lime. Lime is not only a $\mathrm{pH}$ modifier, but also the pyrite depressant.

(2)As an auxiliary collector, kerosene can play a role in the auxiliary collecting by enough time of mixing.

(3)The bulk flotation results show that using $\mathrm{z}-200+$ kerosene as collectors in $\mathrm{Cu}-\mathrm{Mo}$ mixed flotation, at $\mathrm{pH}=12, \mathrm{Cu}-\mathrm{Mo}$ concentrate with $\mathrm{Cu}$ and $\mathrm{Mo}$ grade of $27.545 \%$, and $2.737 \%$, and $\mathrm{Cu}$ and Mo recovery of $92.832 \%$, and $92.091 \%$ were obtained.

\section{Acknowledgment}

The National Science and Technology Support Program of China and National High Technology Research and Development Program of China during the 12th Five-year Plan Period (2012BAB10B08, 2012AA062402and 2012AA062403)are strongly acknowledged. The authors are also grateful to all members in the National Engineering Laboratory of Biohydrometallurgy.

\section{References}

[1] X.Chen, Experimental investigations of selection of the inhibitor of copper-molybdenum separation for copper-molybdenum mixed concentrate, Northeastern University.(2012)

[2] G.Y.Xie, Mineral processing, second ed., China University of Mining and Technology Press, Beijing, 2010, pp. 434-460.

[3] D.Z.Wang. Resource processing, First ed., Science Press,2005, pp. 219.

[4] J.G.Zhu, Flotation reagent, Metallurgical Industry Press, Beijing, 1993, pp. 9-10. 